\title{
CONTENT SHARE IN CMS
}

Xianfeng $\mathrm{He}^{1}$, Chunlu $\mathrm{Li}^{1}$, Mingtian Wang ${ }^{1,2, *}$, Yongkang Luo ${ }^{1}$, Yingwei $\mathrm{Ai}^{3}$

${ }^{1}$ Sichuan Rural Economic Integrated Information Center, Chengdu, 610072, China

${ }^{2}$ Agronomy College, Sichuan Agricultural University, Yaan, Sichuan 625014, China

${ }^{3}$ College of Life Sciences, Sichuan University, Chengdu, 610064, China

" Corresponding author, Address: Sichuan Rural Economic Integrated Information Centre, No. 20 Guanghuacun Street, Chengdu, Sichuan, 610072, P. R. China, Tel: +86-28-87364604, Fax:+86-28-87343798, Email: wangmt0514@163.com

Abstract: This paper is on the background of content share in CMS implemented in Sichuan Rural Economic Information Net, discussing the intentions and significances of content share. Instances during application are demonstrated.

Keywords: Content Management System (CMS), Content Share, Navigation Category

\section{BACKGROUND}

Sichuan Rural Economic Information Center is a government organization dedicated in the information service to agriculture, rural areas and peasants. It consists of one provincial center, 21 municipal branches, 188 county-level service stations, 3380 township-level service stations, and 100 market service stations. Sichuan Rural Economic Information Net is a web portal under Sichuan Rural Economic Information Center and its daily information is managed by the Content Management System (CMS) which is based on the web.

APLAWS+ (Accessible \& Personalized Local Authority Websites) (http: //aplaws.sf.net, 2004) is a national technological standard launched by the UK government for the project of e-government (http://www.govtalk.gov.uk, 2004). It is a system which develops and enlarges itself on the basis of 
Redhat CMS. Sichuan Rural Economic Information Net has built a content management system at all levels in Sichuan Province by applying the open source of APLAWS.

Sichuan Rural Economic Information Net consists of websites such as Chinese version, English version, and Call Center at the province-level and 21 second level websites operated by municipal branches.

Many challenges are faced in the process of building a 4-level application system in the angle of content share:

How can one content item shared among different "navigation categories". In other words, once a content item created, how to make it appear in several categories or subcategories;

How can one "navigation category" shared between province-level and city-level websites. In other words, once a content item created, how to make it appear in different websites;

How to establish its own particular features while share the same content among different channels and websites-"navigation categories" are not contained in content share;

How to make the contents be directly acquired or understood by other websites with the same or different structures;

How to realize the exchange of contents between two same (different) structured content management systems by RSS. For example, to exchange contents between APLAWS and OpenCMS (http://www.opencms.org, 2000).

\section{SHARE OF CONTENT ITEM IN NAVIGATION CATEGORIES}

Navigation category is a basis of content category in content management system. In public users' view, content category shows the function of navigation. Therefore, navigation category manages information in accordance with the core of content information-standard of content category. It is evident that navigation category is the building line of content management.

In CSM, content item is a byword for document files, images, audio files and videos. Usually, one single content item has connection with one category. However, it is often happened that one single content item belongs to both category A and category B. For example, a news item which belongs to three categories: "domestic news", "provincial news", and "hot spot", it can be easily realized that this item be put into these three different categories in APLAWS CMS. (See Figure 1) 


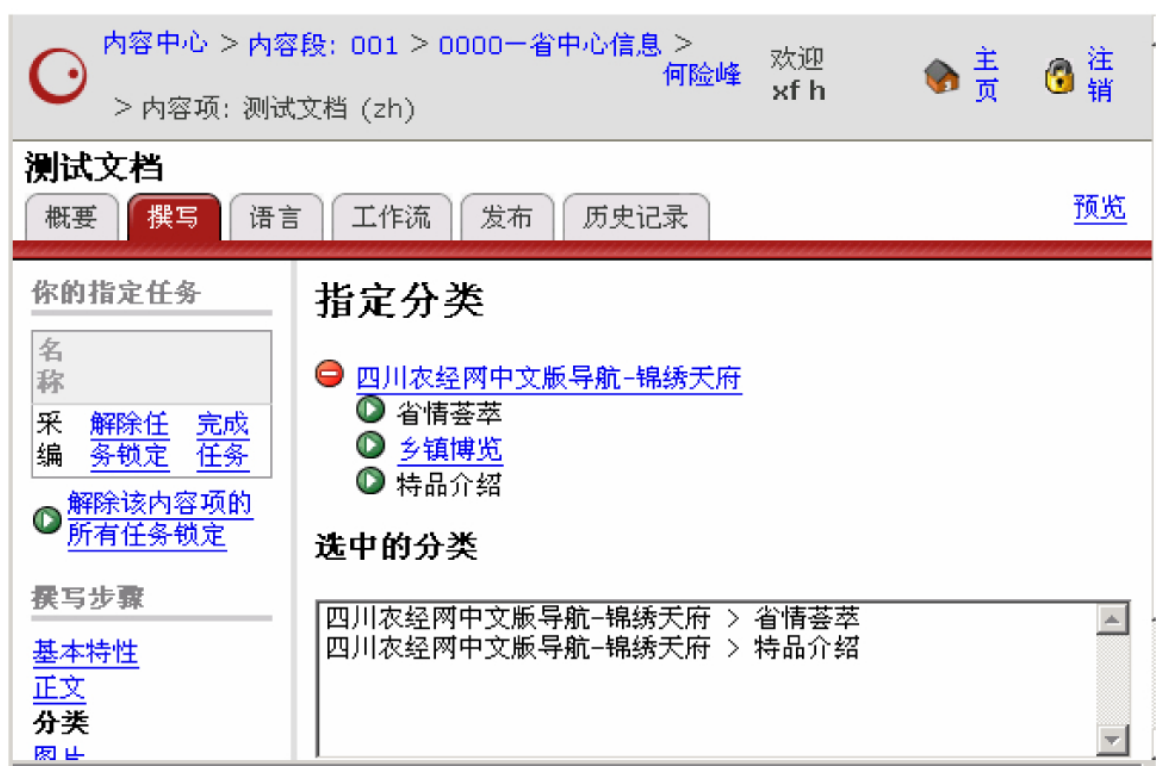

Figure 1. The test item belongs to two different categories

\section{SHARE OF CONTENT ITEM IN NAVIGATION CATEGORIES OF DIFFERENT SECTIONS}

In order to represent the particular features of different channels or sub sites, keep apart administrators of different websites, ease the pressure of web servers and database servers, the concept of section has been introduced in APLAWS (http://aplaws.sf.net, 2004). In the angle of Web Application Framework (WAF), each section has a corresponding web application. In the CMS, content center is a gathering of sections.

Usually each section has its own navigation category. However, it doesn't mean one navigation category can serve only one section, but much more. In other words, one navigation category can be used in different sections. (See Figure 2)

The example of figure 2 is a tree diagram of category of Institute of Plateau Meteorology in Content Section. (There are first level categories such as "organization structure", "scientific and technical personnel", etc.) Categories in Section 001,002 and 003 are also introduced into Content Section. If the tree diagram of category of Institute of Plateau Meteorology 


\begin{tabular}{|c|}
\hline Ex \\
\hline PLAWS RSS Feed List \\
\hline Local Custom Navigation \\
\hline $\begin{array}{l}\text { Local Government Audience } \\
\text { Type List }\end{array}$ \\
\hline $\begin{array}{l}\text { Local Government Category } \\
\text { List }\end{array}$ \\
\hline$\frac{\text { Local Government }}{\text { Directories List }}$ \\
\hline 成都区域气象中心 \\
\hline 高原所导航 \\
\hline 南充市衣业产业信息网 \\
\hline 四川衣经网英文版导航 \\
\hline 四川衣经网中文版导航-供求热线 \\
\hline 四川农经网中文版导航-价格行情 \\
\hline 四川衣经网中文版导航-锦绣天府 \\
\hline 四川衣经网中文版导航-内部信息 \\
\hline 四川衣经网中文版导航-衣博会 \\
\hline 四川衣经网中文版导航-衣业科技 \\
\hline 四川衣经网中文版导航-企业之窗 \\
\hline 四川衣经网中文版导航-气象服务 \\
\hline 四川衣经网中文版导航-人才劳务 \\
\hline 网中文版导航-市场信息 \\
\hline
\end{tabular}

䇾告: 修改将导致失去下次用 ESD Toolkit 升级域的机会

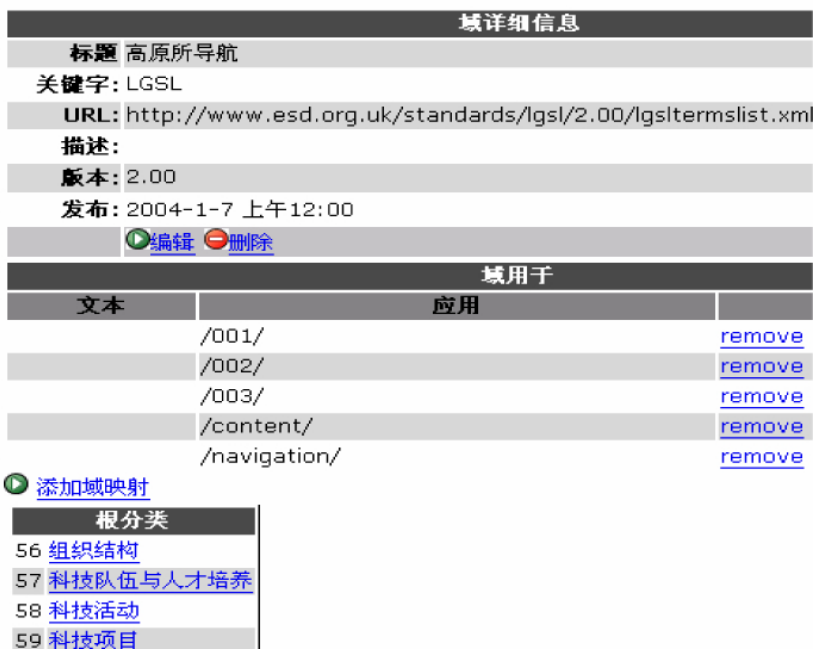

Figure 2. The navigation category of Institute of Plateau Meteorology shared by Section 001, 002 and 003

under Content Section is introduced into other sections, administrator can create a new item in one of the sections and put it into the same category, take "organization structure" for instance, then this newly created item can be seen in all "organization structure" in different website navigations-the realization of sharing content item in navigation categories of different sections is achieved.

\section{CATEGORIES WITH PARTICULAR FEATURES}

If all sub sites in CMS share the same information with each other and don't have its own information, it will bring us the feeling of similarity and we will lose control in content management. Therefore, the balance between content share and particular feature is very important. For example, sections with the feature of "prices" should not contain information of sections with the feature of "news"; Sections with categories served for "province-level" should not accept categories from "city-level" sections; However, categories in "city-level" sections" should take categories at the "province-level" into consideration in order to make the information be shared in Sichuan Province. Figure 2 shows the featured category of Institute of Plateau 
Meteorology in Content Section and at the same time, this section deals with information from Section 001,002,003. The aim of both sharing content in different sections and showing particular features are reached.

\section{EXCHANGE OF INFORMATION BY SEMANTIC XML}

All web pages contain the information in CMS. Theoretically, all contents can be separated from the web page by the method of program analysis. However, too much unexpected information such as locale, colors is contained in web pages. It seems that other ways are necessary for the exchange of information among websites.

The concept of semantic XML has been introduced in APLAWS. It brings the possibility of acquiring pure content information with architecture description by HTTP with "? output=xml".

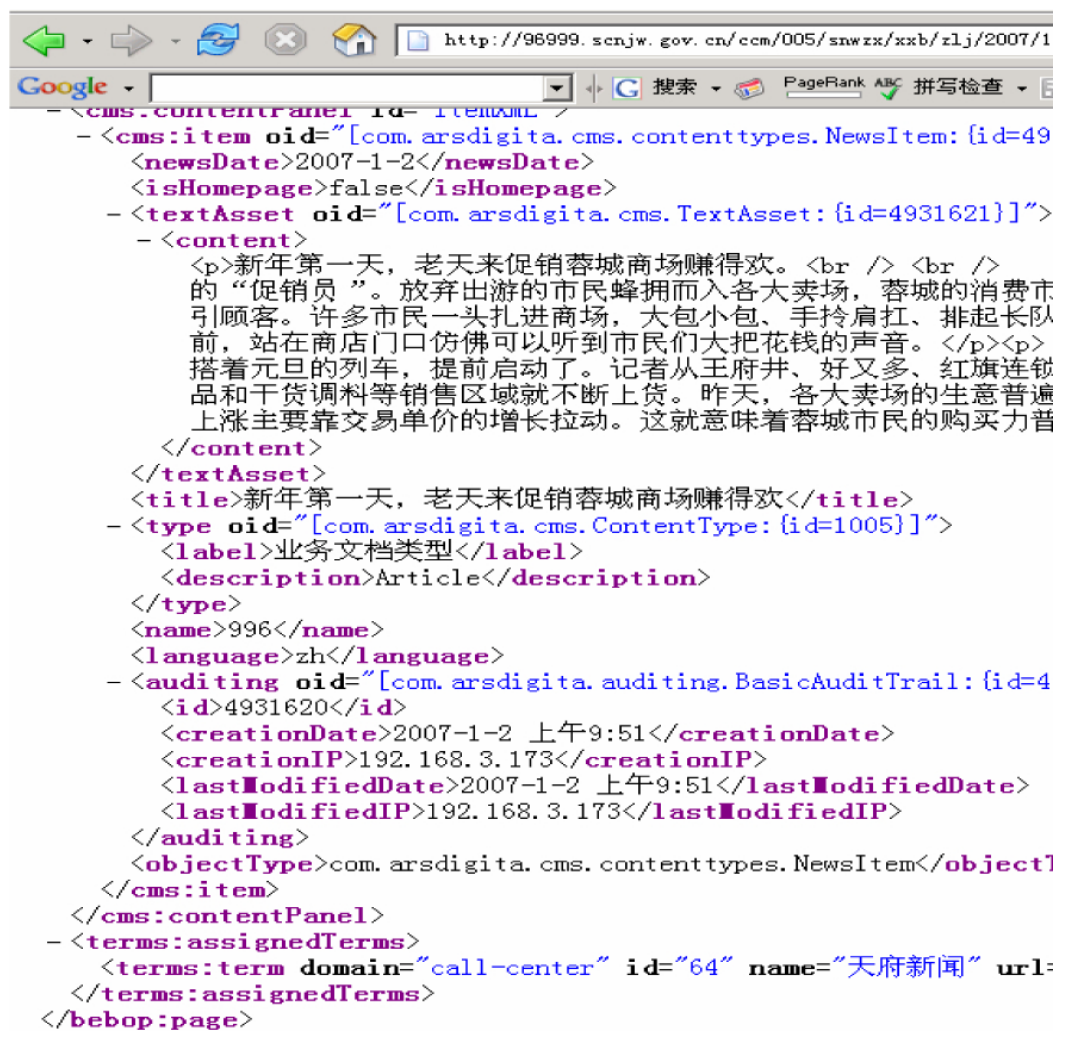

Figure 3. Contents with architecture described by semantic XML 
By entering http://96999.scnjw.gov.cn/ccm/005/snwzx/xxb/zlj/2007/1/996. zh?output $=\mathrm{xml}$ in the browser and transfer the information into XML, result in figure 3 shows. It contains semantic information such as <language>, $<$ title $>$, <content $>$, <auditing $>$, <objectType $>$, <terms.assiegnedTerms $>$. Such semantic XML has established architecture information, so it is not difficult to exchange and share information between two websites.

\section{CONCLUSION}

Through the content share realized in APLAWS CMS, we can understand that content share happened in different levels. The lowest level is to share content within a section; content share among sections can be divided into two kinds: content share section and section with particular features; the concept of semantic XML has built the foundation of sharing information among websites. Besides, APLAWS has provided service in RSS Feed, application of Dublin Core, input and output of XML, etc. They will be introduced specially in other papers.

\section{REFERENCES}

http://www.aplaws.org.uk

E-government plans or standards, please refer to http://www.govtalk.gov.uk 